\title{
An empirical study of mobile-device use at Norwegian oil and gas processing plants
}

\author{
Daniela Blauhut ${ }^{1} \cdot$ Knut L. Seip ${ }^{2}$
}

Received: 28 August 2017 / Accepted: 7 February 2018 / Published online: 23 February 2018

(C) The Author(s) 2018. This article is an open access publication

\begin{abstract}
Mobile devices have been used for at least 5 years in the oil and gas industry. The interaction-design challenge is to develop a holistic view of operator-device interaction in hazardous areas to ensure that this mobile technology best serves the goals of both its end users and the oil and gas organizations. Introducing mobile devices can change the environment, the workers and even the industry's objectives. In this paper, we provided insights into work practices and mobile-device use at two Norwegian natural-gas processing plants. Using methods inspired by ethnographic and interaction-design research, we investigated how operators used their mobile equipment in the field, and we explored the extent to which mobile-device use improved procedures and satisfied users' needs. In contrast to many other studies on mobile-device use, this study drew upon empirical observations of real operations in hazardous environments.
\end{abstract}

Keywords Mobile devices · Interaction design $\cdot$ Ethnographic fieldwork $\cdot$ Oil and gas workplaces

\section{Introduction}

During the past 2 decades, the popularity of mobile handheld devices for use in professional settings has grown significantly. Mobile devices, such as tablet computers and personal digital assistants (PDAs), have been implemented in education, medical practice and industrial plants. In the oil and gas industry, the introduction of electronic devices is subject to strict requirements due to the hazardous environments present in this industry. For example, in oil and gas processing plants, no kind of electronic device that is not certified as safe for use in explosive areas can be used (Heyer 2010). This has implications for design because mobile devices normally become bigger and heavier due to the use of appropriate materials and the encapsulations of product components. For the oil and gas industry, this

Daniela Blauhut

daniela.blauhut@hiof.no

Knut L. Seip

knut.lehre.seip@hioa.no

1 Faculty of Engineering, Østfold University College, P.O.Box 700, 1757 Halden, Norway

2 Faculty of Technology, Art and Design, OsloMet-Oslo Metropolitan University, Pilestredet 35, St. Olavs plass, P.O.Box 4, 0130 Oslo, Norway means that they are harder to use in the industry's hazardous environments and that they hinder the movement of its users. Moreover, the oil and gas workplace differs from other professional settings, as process plants are exposed to extreme weather, noise and danger. Field operators perform their tasks while wearing protective clothing and while equipped with tools and safety devices. Given these challenges, it is unsurprising that motion, vision and mobile-device use are affected.

Paper-based methods for monitoring task performance are still common in the energy industry. In nuclear energy workplaces, paper-based methods are mainly used for prejob briefing procedures and work permits. In the oil and gas sector, they are used for work permits, entrance permits and blueprints. The implementation of mobile devices at oil and gas processing facilities has both advantages and disadvantages.

To meet the challenges of hazardous work environments, ethnographic research and physical work analysis are urgently needed to guide engineers and manufacturers in the user-centred development of mobile devices and mobile interfaces that can effectively support operators. Previous researchers have found ethnographic methods to be useful when exploring work practices in the energy industry. For example, Oxstrand et al. (2013a) carried out on-the-job observations of fieldworkers at a nuclear power 
plant and conducted interviews with them to develop a 'model of procedures usage'. Heyer (2009) went to a Norwegian gas refinery to conduct ethnographic fieldwork that comprised both observational studies and informal interviews; Heyer considered it valuable to be present in a physical plant so as to develop an understanding of its processes and work practices (ibid.: 363). Ethnography (especially video ethnography), though typically adopted in disciplines other than design engineering, has been used often for studying practices and work systems in interaction design [e.g. Farrington-Darby and Wilson (2009) with reference to rail controllers' social interactions].

Science and technology researchers have studied the potential of touchscreen technologies (e.g. Harrison and Hudson 2009; Kuhlmann 2012; Senseg 2014) and of other new artefacts and systems for use in oil and gas processing facilities (Heyer and Hus $\varnothing$ y 2012). Scholars have also contributed to the research on collaboration in plant operations (e.g. Heyer 2009) and provided novel ubiquitouscomputing solutions and prototypes for the oil and gas industry (Heyer 2010). Handheld technologies have been tested to support personnel in gas and nuclear power plants (e.g. Kaarstad et al. 2012; Jokstad 2010; Oxstrand et al. 2013b). In recent years, several industrial companies (e.g. Motorola and Bartec) have also developed rugged, explosion-proof high-tech devices for use in hazardous areas.

We focused, first, on how mobile devices' design affects work practices and those devices' use in hazardous areas. Second, we examined how these effects influence design processes by applying ethnographic methods. We used qualitative interviews, participant observations and video studies to evaluate both the impacts that two mobile devices had when used in a control room and outside of the facility (in terms of both people and work performance) and the current work routines in typical oil and gas workplaces (the Ormen Lange and Hammerfest LNG processing plants).

In the next section, we give brief information about the study sites. In Sect. 3, we outline our methods. In Sect. 4, we present our results; this is followed in Sect. 5 by a discussion on the challenges and opportunities for industrial applications of mobile technologies. We conclude in Sect. 6.

\section{The study sites}

The Hammerfest LNG plant, which is located on the island of Melkøya in Finnmark, Norway, processes and condenses gas from the Snøhvit field; Statoil operates this plant. At the Ormen Lange gas plant, which is located at Nyhamna in Aukra, natural gas from the Ormen Lange field is processed and exported; Shell operates this plant.

\section{Methodology}

In this study, we focused on learning about work practices and operator interactions at natural-gas processing plants as well as on understanding the challenges of operating these plants. Further, we were interested in how the mobile equipment design affects work practices.

We carried out our fieldwork studies in three phases: Ormen Lange I, Hammerfest LNG and Ormen Lange II (in chronological order). Using an ethnographic approach that included active participation, we observed nine operators and interviewed eight operators and engineers. Table 1 provides a description of our research activities, including the methods we used in each phase and the studies' participants, purposes, durations and equipment.

\subsection{Participants}

The operators who participated in the interviews about the TETRA terminal had been trained in engineering (production, process and electrical) and in instrument maintenance. The engineers and the operator who participated in the open interview about the PDA had backgrounds in information management and technology and in process engineering. We asked the participants to bring their mobile devices with them to the interviews.

The operators whom we observed had to perform a variety of tasks. When we visited Nyhamna for the first time, we observed two operators checking the plant's substation ventilation and testing the ventilation flaps. These operators were equipped with headsets, gas detectors, TETRA terminals, remote push-to-talk (PTT) buttons, mechanical tools and a stack of paper-based work permits. They wore safety boots, high-visibility protective clothes, gloves and protective glasses - as did we. During our second visit to Nyhamna, we taped observations during logging rounds, as four operators inspected equipment and collected processing data such as pressures and temperatures. In addition to the usual equipment and protective clothing, they carried PDAs to scan barcodes.

We taped observations of three operators while visiting Hammerfest LNG. One worked in the central control room and controlled one of the four control stations. The other two inspected the processing facility, a task that included controlling pumps and valves, as well as signing and administering work permits. They wore protective clothing, including gloves and glasses, and were equipped with gas detectors (clipped to the pocket), remote PTT buttons (clipped to their jackets), a portable radio (fixed on their belts), tools (in their inside jacket pockets) and helmet lights. 


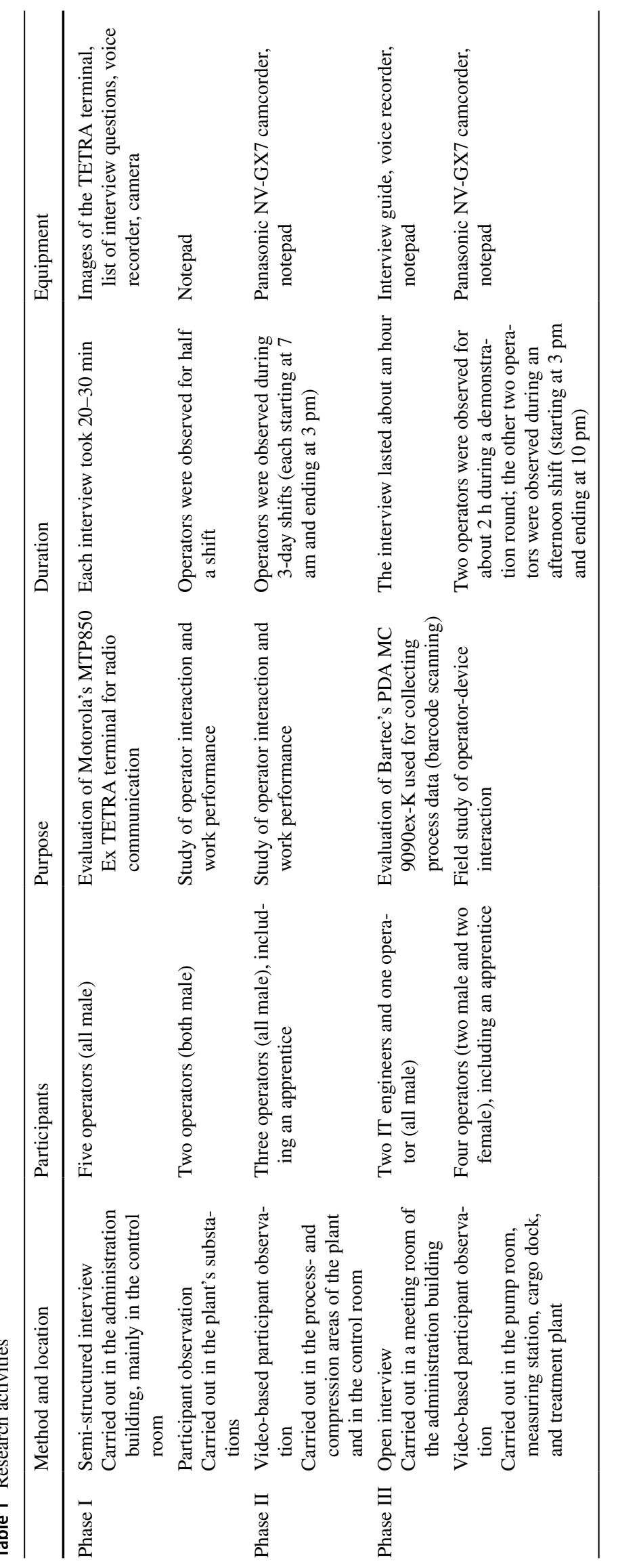




\subsection{Procedure}

We used two main methods in our field studies: qualitative interviews and video-based participant observations. In the interviews, we asked about the operators' views on the functionality, user interface and ergonomics of the TETRA terminal or the PDA. We also asked about their first uses of the devices, their expectations and the devices' effects on both procedures and users. These interviews' purpose was to understand how the designs of a TETRA terminal or a PDA affect operator-device interaction. We focused on usability and workflow improvements and thus on how the designs affected the plants' efficiency, safety and work performance. To acquire detailed insights into the field operators' everyday work, we participated in inspection and maintenance fieldwork and videotaped seven participants. We used a video technique known as shadowing, in which the observer follows the user's daily routine (Sperschneider et al. 2006). We also applied a technique called simulated use (ibid.), in which an operator simulates two very short alarm situations to determine the extent to which acoustic warnings can be missed due to the processing plants' extremely high noise levels. (It turned out that the combination of acoustic and visual indications that the portable gas detectors gave could not be ignored.) Although we planned the shadowing, we applied the simulated use spontaneously. In addition, we applied various camera styles (e.g. surveying and engaging) to provide an overview of the environment and to show other people's perspectives (cf. Blauhut and Buur 2009).

\subsection{Ethical and safety aspects of video observations}

One limitation to our study arose from an ethical question, as recording people requires adherence to ethical standards. This includes obtaining permission for data collection, sending advance information to about the study's background and about how the gathered data will be used, showing respect for the informants' privacy and preserving their anonymity, and providing the data to the participants after the analysis is complete. We found it useful to have the participants review our written reports and provide feedback on our video artefacts so that we could be sure that the participants felt comfortable with our representations (cf. Blandford et al. 2015). The presence of a video camera can influence situations and the people being videotaped. However, the role that the camera plays in building rapport with the studied operators is not known. Despite our efforts to observe and record from a respectful distance, we had the impression that some operators felt uncomfortable when the camera was pointed at them for long periods, especially when relatively idle. Therefore, we turned the camera off from time to time instead of running it continuously. This had an impact on the analysis, however, as it prevented the creation of accurate timelines for the individual operations.

Non-explosion-proof photography and filming equipment with batteries and/or flashes are classified as Class B ignition sources, as they can produce incendiary sparks. ${ }^{1}$ The technical personnel in the process and compression areas of the plant approved our filming, and we agreed not to use flashes when taking pictures. (In administration buildings, there are usually no restrictions on the use of film and photography equipment.) We kept the technical equipment to a minimum by capturing the video footage with a simple Panasonic NV-GX7 camcorder.

\subsection{Analysis methods}

In our analysis, we started by transcribing the interviews and recordings using the Transana open-source transcription and analysis software, which was developed at the Wisconsin Center for Education Research at the University of Wisconsin-Madison (Barclay 2012). We than identified six main text segments that contained meaning units, using them to create six main categories and 31 subcategories (corresponding to 31 labels), into which we assigned the text segments. We used the same transcription and analysis software tool for the audio data from the videotapes. In addition, we used Ulead VideoStudio 10 to edit the video material. We created seven long films and eight short clips (each of 7-8 s) from the film stock recorded at Hammerfest LNG, as well as five long films and eight short clips from the film stock recorded at Nyhamna. Later, we arranged the clips into two video collages in which each clip ran in a loop. We selected the video segments for the films according to two criteria: understanding the context and highlighting the phenomena of physical activity and device interaction. The primary purposes of the video collages were to study and compare typical body postures during task performance and to look closely at operator-device interaction (so as to determine the challenges involved).

In addition, we documented nonverbal material using images and by means of three interactive infographics that allowed us to put a large amount of information into each graphic without overloading the reader. Because these infographics have many layers, not all of the information is presented at once, thus encouraging researchers and industry professionals to engage with the subject by clicking on hyperlinks to get more information. In our examples, the hyperlinks pointed to video clips and images that provided details on the operators' tasks and motions, as well as to

\footnotetext{
${ }^{1}$ Class B involves flammable gases or liquids (Statoil n.d. Facility specific HSE manual for Hammerfest LNG. Appendix to the GL1122 personal HSE manual, p. 15.).
} 

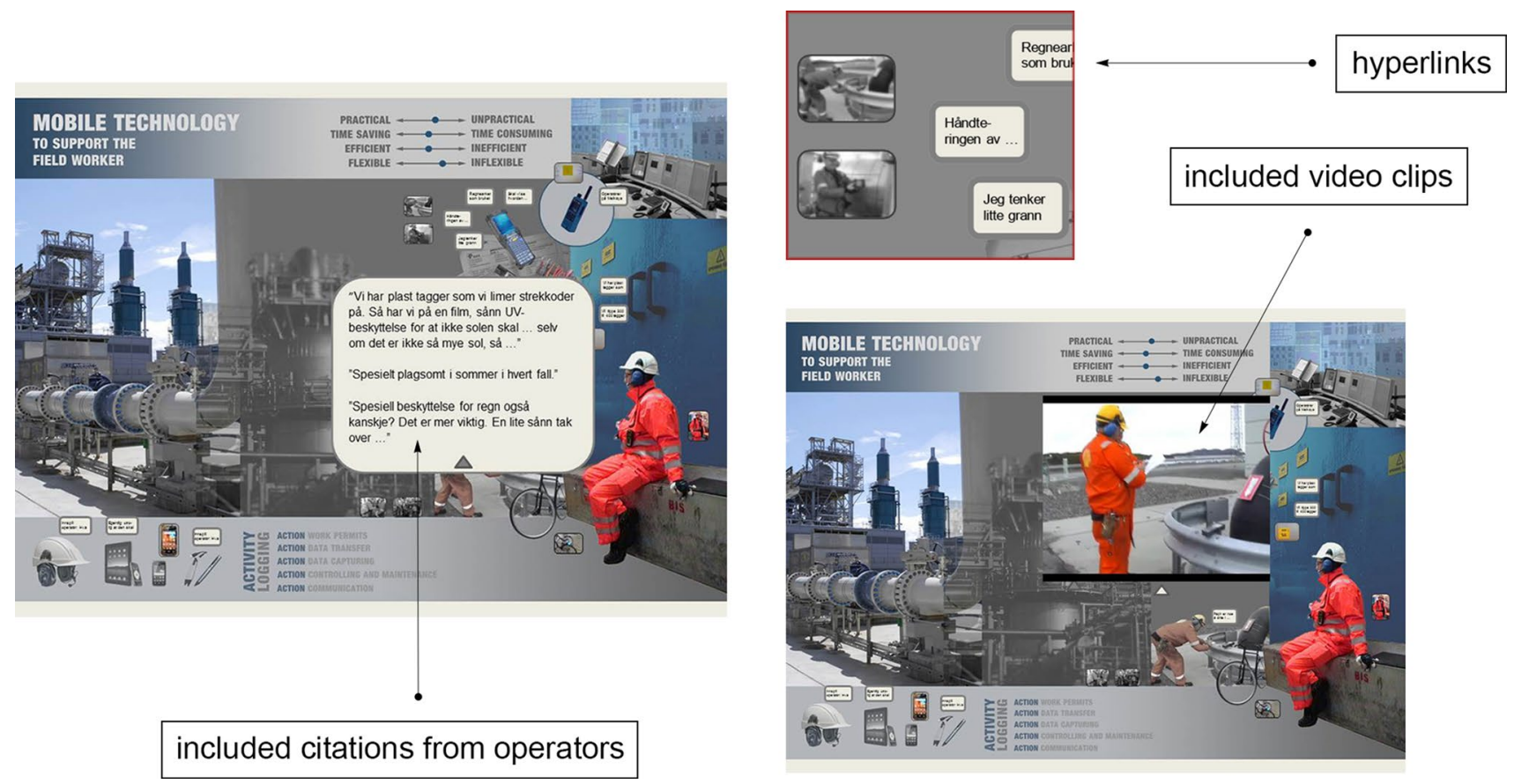

Fig. 1 Example of an interactive infographic, including citations and video clips that visualize parts of the data collection and that outline problems observed in the field

citations in which operators provided detailed feedback on their device experiences. Figure 1 shows an image from one such infographic.

\section{Results}

We structured this paper according to two key themes. First, we evaluate two handheld devices; then, we consider the work practices and operator interactions in oil and gas workplaces. In the following sections, we report on these themes and discuss our findings.

\subsection{Evaluation of two handheld devices}

\subsubsection{Motorola's MTP850 Ex TETRA terminal (as used at Nyhamna)}

Handheld radios are used at Nyhamna for permanent communications with the central control room (Fig. 2). In the following, we briefly report on some of the findings from our interview analysis. We focus on four issues: technological complexity, user expectations, workplace design and introductory processes.

\subsubsection{Technological complexity Many electronic} devices include features that are not necessary in a plant environment. In some cases, such features can actually be detrimental. The digital TETRA radio from Motorola, for example, includes advanced functions such as a "man down' alarm that the managers at Ormen Lange do not need. Advertisements for the product promoted this function as a way to increase operational safety; however, it has disadvantages. The function can be activated even when the radio is stationary-for example, if it is placed on a table for a while-thus causing unnecessary alarms.

Other features, including the integrated text tool, are difficult to understand because the device does not have a keyboard for text entry. Users have to rely on predefined messages from a menu. During our interviews, participants repeatedly stated that such a tool is not needed.

4.1.1.2 User expectations Blauhut (2016) discussed experiences and motoric habits in terms of tactile perceptions of mobile devices, underscoring that spatial memory provides humans with spatial orientation that enables users to find what they expect to be the correct function or button without looking at the device. In the case of the TETRA radio, users initially confused the emergency button, which is located on the top of the radio, with the power button. The users' expectations were based on their experiences with previous devices, each of which had a similar-looking button (with a different function) in the same place. The workers discussed this problem with Shell and with employment-protection representatives. Based on this information, Shell made a couple of changes. How- 


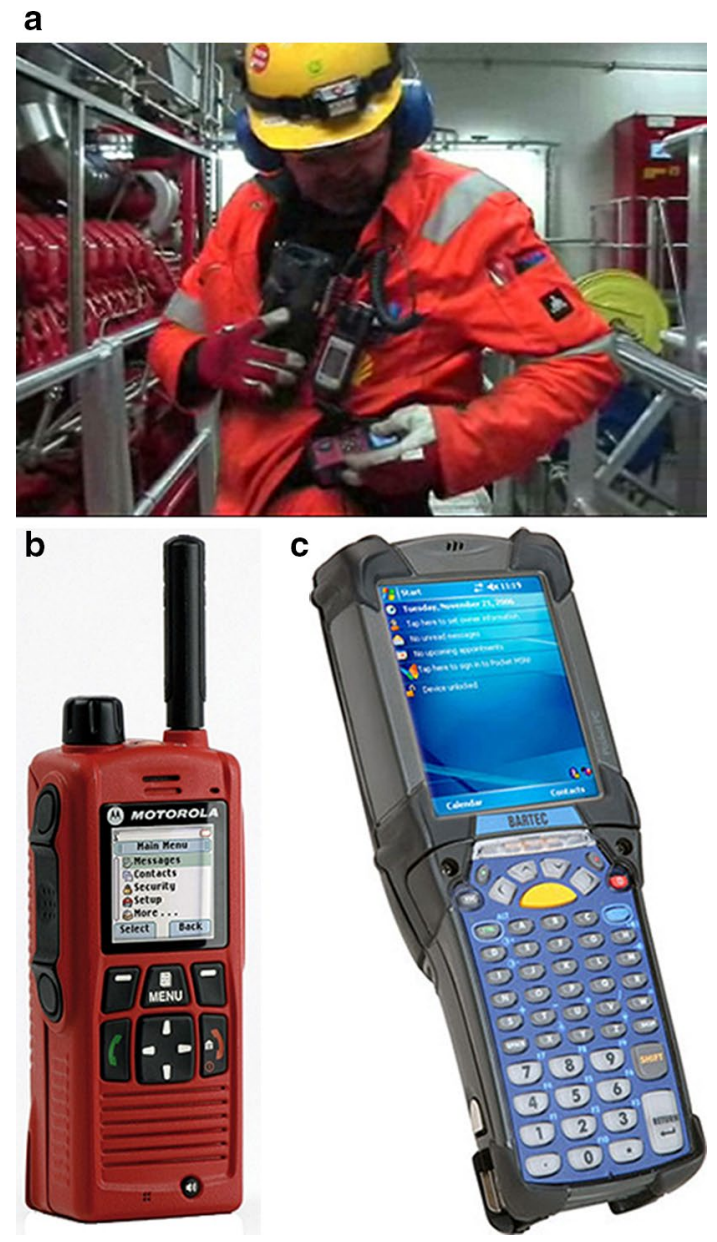

Fig. 2 Operator at Nyhamna carrying equipment: a handheld radio, PDA, gas detector and tools; b Motorola's MTP850 Ex TETRA radio; and c Bartec's MC 9090ex-K PDA

ever, any unintentional activation of the emergency button can cost a company time and money.

4.1.1.3 Workplace design The physical design of large industrial facilities such as Nyhamna affects the quality and range of radio signals. Radios' effective ranges depend on a facility's layout (e.g. the use of open and enclosed spaces), its construction (e.g. the number and thickness of its walls, the materials used and the number of elevator shafts) and its number of base stations. At Nyhamna, coverage is poor in certain enclosed spaces. Because radio communication is critical for plant operation, the loss of radio signals poses a risk to health and safety.

4.1.1.4 Introductory processes In our usability study, we further revealed critical issues regarding a technology's introductory and transitional periods. Based on the interviews, we noticed that the operators experienced the TETRA radio differently. Some had no problems, but others continued to rely on their analogue radios instead. However, new technologies and modifications to existing systems are always associated with uncertainty and scepticism among potential users. A clear presentation of the issues that such new technologies address, as well as of their advantages compared to previous technologies, can help generate wider acceptance among those whose work is influenced by these new solutions. In addition, a welldesigned transition phase should include sufficient time for testing the new technology. Involving the users of the technology in this process can increase their acceptance of the new instruments. Finally, instructions and training on the use of new technologies can prevent abuse.

\subsubsection{The handheld MC 9090ex-K PDA (as used at Nyhamna)}

Next, we provide a brief overview of the usability issues related to the handheld MC 9090ex-K PDA. We focus on four problems: ergonomics and overall product design, graphical user interface, the psychological effects on users and workplace design.

4.1.2.1 Ergonomics Our data analysis of Nyhamna's logging procedures showed that end users struggled with the handheld device, which was difficult to handle due to its weight, its size and the design and arrangement of its individual elements (e.g. the scan exit window). The product is rugged and compact because it is supposed to be used in harsh environments (see Fig. 2c). In addition, it must comply with the Atmosphères Explosives directives for explosion protection to ensure that it is intrinsically safe for use in explosive environments. However, our study showed that the MC $9090 \mathrm{ex}-\mathrm{K}$ had a negative impact on operators' mobility. We identified the operators' movements and postures in the plant setting via video artefacts and infographics. Against this background, the question arises as to whether future mobile devices targeting the oil and gas industry should be designed using wearable-computing criteria. The main difference between mobile devices such as PDAs and wearable devices is that the latter are worn on the body during use (under, within or on top of the clothing). Wearables thus support hands-free actions, which is particularly helpful in a demanding environment. It is worthwhile for future researchers to use the wearables approach, which focuses on actions taken in the real world with the aid of mobile devices, instead of focusing purely on the operation of mobile devices. In our interviews, the operators also mentioned that certain features of the PDA, such as the keypad, were rarely used. We obtained similar results in our investigation of the TETRA terminal. 
4.1.2.2 Graphical user interface Display legibility depends on surroundings, lighting conditions and (particularly) screen technology. Nevertheless, a well-designed interface is of great importance in ensuring that a device can be used effectively. Designing text presentations and visual content for small-screen devices poses a special challenge, as the factors listed above can all affect readability. The Nyhamna field study revealed that environmental factors - in particular, direct sunlight and rainplay an important role in the use of the PDAs. Designers and engineers must therefore develop product concepts that address the specific needs of operators who work in demanding environments. Another challenge is the lack of screen space. This leads to a need for dynamic space organization, which is one of the most difficult aspects of design, as the amount of information that must be communicated is usually high.

4.1.2.3 Psychological effects on users In the sections on the TETRA terminal, we stressed the importance of introducing each new technology to achieve better user acceptance. This can be illustrated via an example: Some of the operators were concerned about possible side effects of PDA use, in the sense that it could have a controlling effect on the workers. The practical application of the PDA in the plant setting included functionality that allowed for control over inspections and for tours to be precisely monitored after the data had been transmitted. However, the main purpose of this application was not to monitor users but to ensure that facilities and equipment are inspected periodically (in turn ensuring that the plant is operated in a safe manner). The social and psychological aspects of information technologies that record data must be considered when launching new systems. The use of the PDA is a safety matter; thus, it is important to communicate the device's purpose and benefits to users and to provide them with valuable context.

4.1.2.4 Workplace design Our study on the data-logging processes at Nyhamna showed that barcode tags were not always easy to identify. They were mounted on various components and equipment that was arranged in a physically complex environment; construction, assembly and surface structure determined each object.

In summary, although the implementation of a mobile data logger has improved previous inspection procedures (by replacing paper-based checklists), there is still room for improvement in terms of efficiency. The organization followed the Nyhamna field study with an evaluation of the organization's entire data-logging project. This project improved the logging rounds. Nevertheless, the company abandoned its use of the PDA device, and in 2017, Nyhamna's operators went back to using checklists.

\subsection{Work practices and operator interactions in oil and gas workplaces}

In the following three sections, we provide insights into work practices and operator interactions in oil and gas workplaces. Our studies of Ormen Lange and Hammerfest LNG revealed three main problems related to (1) paper-based practices, (2) the Hammerfest LNG plant's orientation guides and (3) mobility.

1. Paper-based practices Although the observed work domain is technologically advanced in terms of process automation, nondigital objects are still important in current work processes; they often serving as links between the digital world and the real world (cf. Heyer 2009). For example, workers used pocket notepads to write down information (e.g. numbers of work permits, part numbers and notes) that they later entered into a digital system using the desktop computers available in the plant's offices and workstations. The work permits existed in digital form in the enterprise resource planning system but were printed out to provide operators with paper documents. The documents were physically archived when the work was complete, after all required signatures had been appended to them.

2. The Hammerfest LNG plant's orientation guides At Hammerfest, Statoil cooperates with various contractors, particularly in the context of repair and upgrade work. This means that Statoil does not employ many of its own operators and that first-time operators (e.g. vendors or assemblers) frequently work there. The plant's design is logically and physically complex, involving compressors, valves, high-pressure pipes and explosive materials. Although experienced operators know their work areas, first-time operators are not familiar with the plant and thus depend on local-orientation aids to support their perceptions and activities. The plant's lack of orientation guides imposes could lead to potential dangerous situations for operators and could cause timeconsuming work processes.

3. Mobility In addition to the strict design requirements for electronic devices used at such plants, the area's weather conditions, the facility's complex infrastructure and the equipment's intricacy all impact the operators' mobility. As we noticed in our video collages, field operators are supposed to be flexible, both when moving around the plant and when performing tasks. This often forces them into unnatural and uncomfortable body postures. Figure 3 gives an impression of how operators perform their actions.

In addition, operators must pay attention to each of the many pieces of equipment they carry when in the field. They 

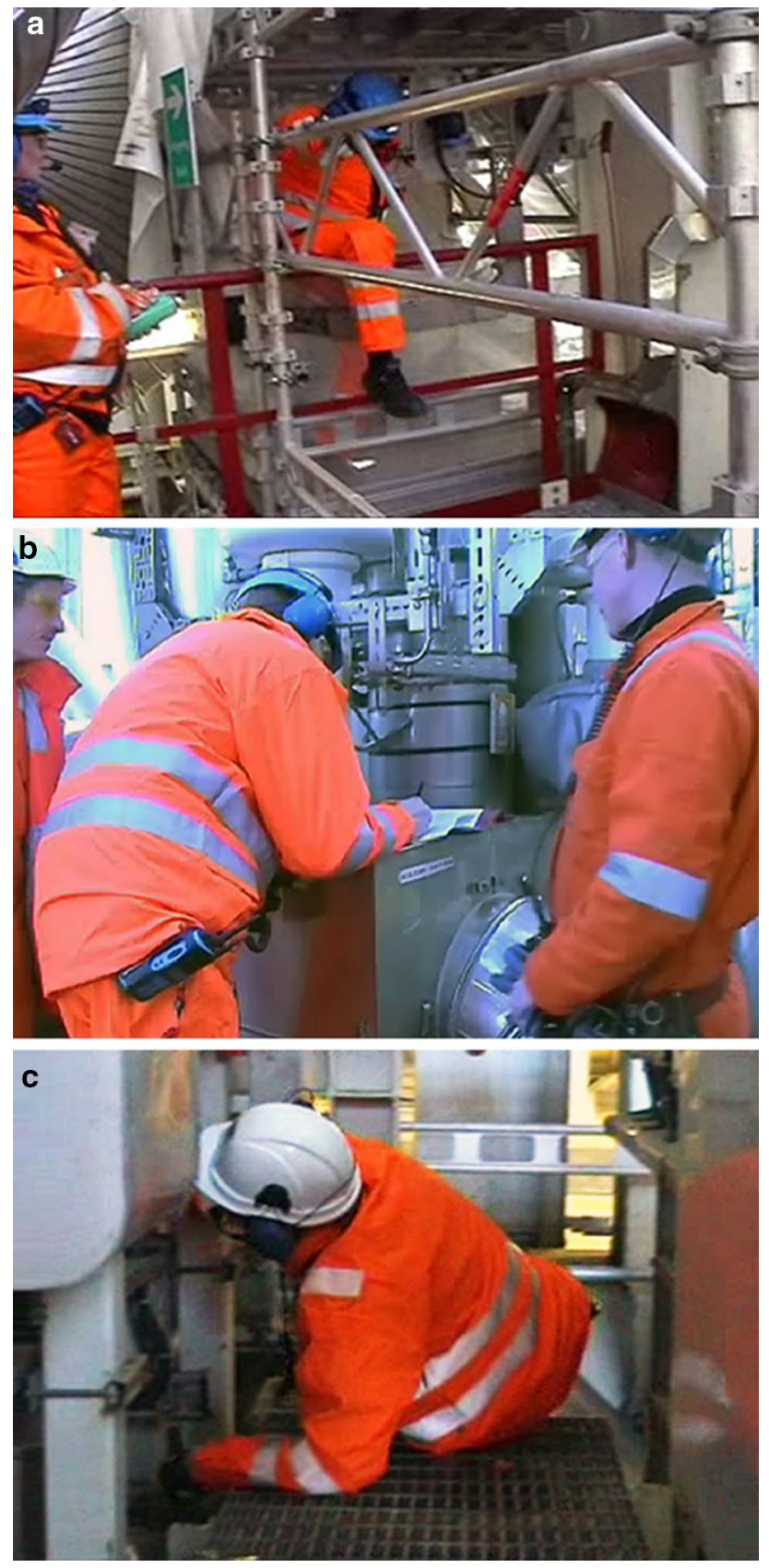

Fig. 3 Operators at Hammerfest LNG performing actions in a hazardous environment, a moving through a network of pipes and valves, $\mathbf{b}$ signing work permits on the solid surface of a plant component and $\mathbf{c}$ controlling valves

are usually equipped with tools (primarily worn on a tool belt), technical safety devices (such as gas detectors), portable radios, headsets, PTT adaptors, measurement instruments, mobile phones and paper-based equipment (such as blueprints and work permits). Moreover, they must wear protective clothing. At Nyhamna, during its 4-5 years of use, the MC 9090ex-K mobile computer affected some operators, negatively influencing their mobility. Due to the device's weight and size, it could not be easily worn on the body. Instead, operators had to hold these devices in their hands for a long time. From a technical perspective, we assessed human mobility and evaluated the handheld equipment's technical aspects that support mobility. From an interactiondesign perspective, we considered operator-device interaction, which includes technical, design, and human factors.

\subsubsection{Further insights into operations activities}

Devices such as PDAs have complex functions that do not fit with the ways in which plant operators perform their actions. When we observed Nyhamna operators on their inspection rounds (in which they recorded process data), they used bicycles to get from location to location. Before the operators could start logging data, another worker asked one of them to sign a work permit. As the PDA was too large to be worn on the body or to be clipped to a belt, the operator placed the device on the rear rack of her bicycle before signing the work permit for her colleague. Then, when the group was about to continue by bike, she almost forgot the device on the rear rack. This scenario shows that current barcode-scanning equipment poses challenges for operators, particularly in terms of safe storage when it is not in use.

The study on PDA's usability also showed that its scanning procedures became cumbersome if operators, for example, could not see whether they had hit the barcode or not [operator: "If you see here now,... here the scan... the lack of light that we have... you do not see what's up... if you've hit or..."]. Both the display's legibility and the red laser's identification ability depended on the visibility and lighting conditions (see Fig. 4a).

The most obvious problems with the PDA were its size $(231 \mathrm{~mm} \times 91 \mathrm{~mm} \times 105 \mathrm{~mm})$ and weight (approximately $1 \mathrm{~kg}$ ). However, the product was designed for use in hazardous environments, which means that it must be rugged, compact and protected from becoming an ignition source. It is thus a challenge to make it smaller and lighter. During work, operators normally held their PDAs in their hands (see Fig. 4b). Strong wind affected the scanning procedures, making it became more difficult for operators to steady the device and scan it.

In addition, although the use of wireless technology has increased over the past decade, paper-based methods for task performance are still common in the energy industry. For example, on a cold and windy day, we observed a plant operator carrying blueprint pages of A3 size $(297 \times 420 \mathrm{~mm}$, as defined by the ISO 216 standard) with drawings of pipes and valves. His tasks were to measure gases and remove the hydrocarbons from a specific valve that was going to be replaced. He later labelled the inspected valve using a red, laminated sign. Our informant noted that he had to browse through up to 10 blueprints at times in order to find the right 

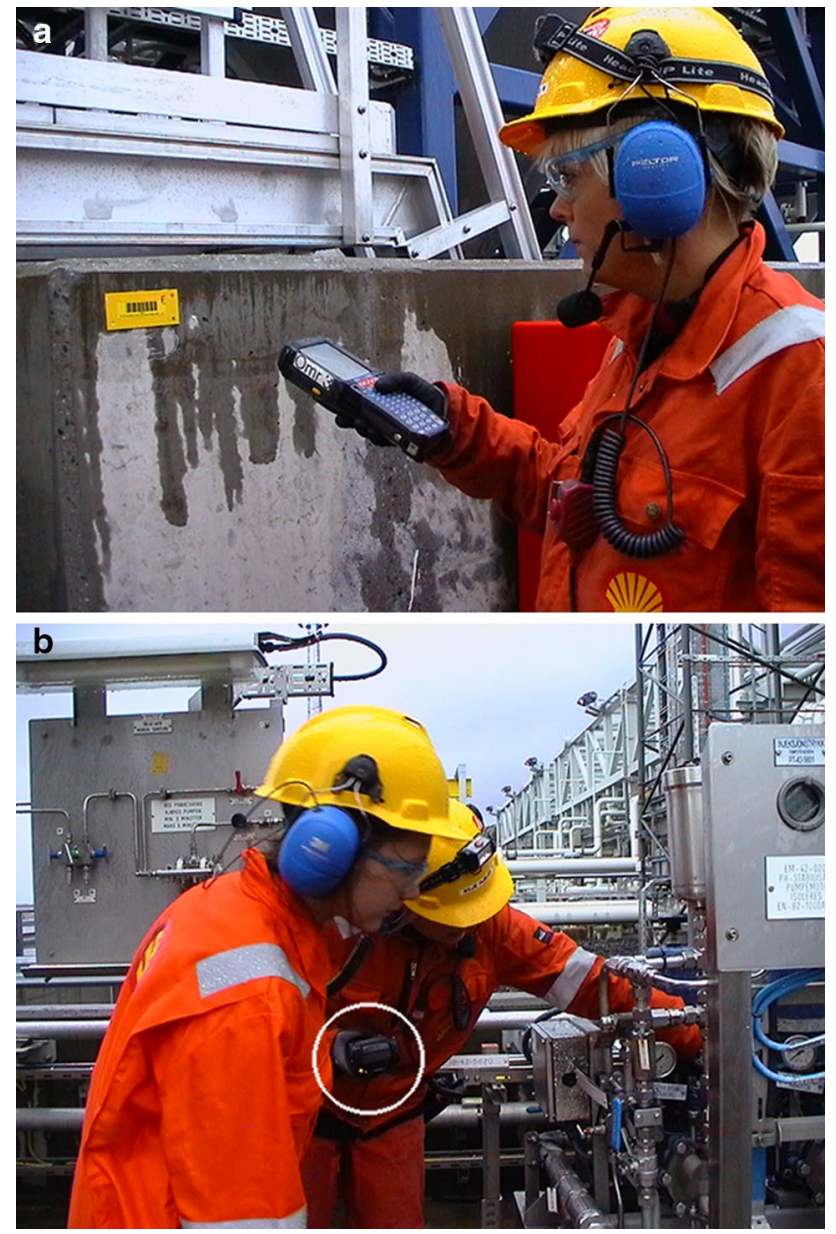

Fig. 4 Ergonomic challenges related to scanning with a PDA: a aligning the scan exit window correctly and detecting the laser beam; $\mathbf{b}$ the device's constant presence

valve or pipe for such a task. This scenario shows that there is a need for improvement in the current work practices, especially considering the weather conditions in the area.

\subsubsection{Design impacts}

Based on our findings, we suggest, first, that mobile devices should provide intuitive, tactile product cues (e.g. the geometric shapes and textures of product components) to ensure that users can quickly access primary product functions.

Second, regarding the question of how successful designers have been at providing devices that support practical use, we argue that the impact of human motion on interactions with screen-based computer devices has not yet been sufficiently explored for hazardous industrial settings. In the case of operator-device interaction, operators' ability to perform bodily movements was determined by not only the device's size and weight but also by the
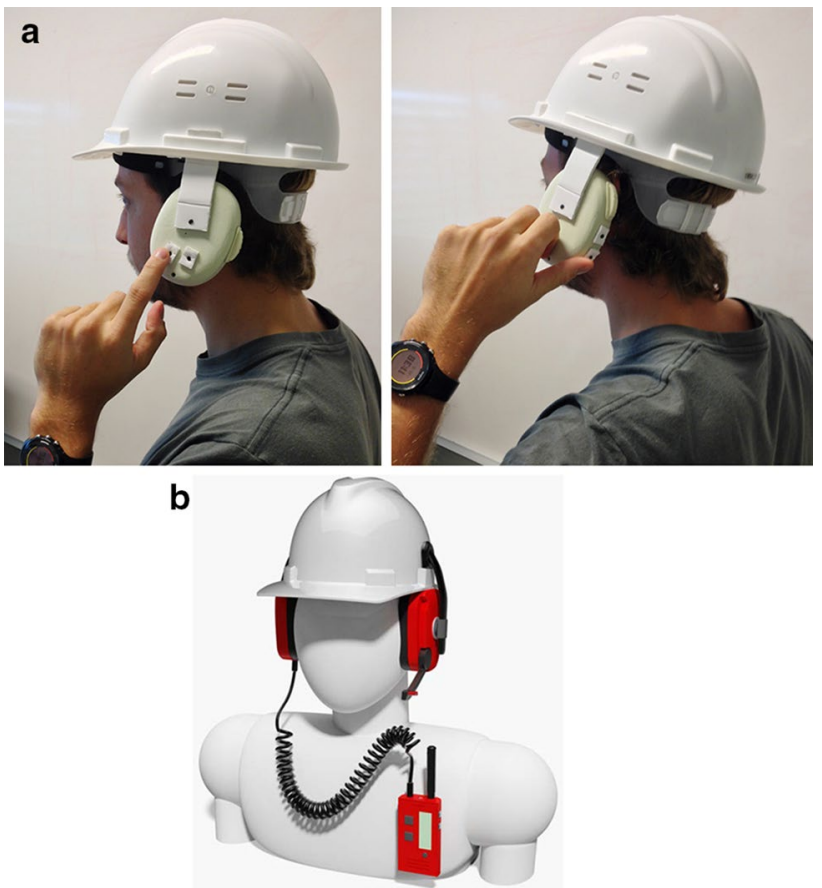

Fig. 5 Designing towards user acceptability and ease of use: a simple headset mock-ups for testing possible positions of elements that control the volume, channel and PTT; $\mathbf{b}$ 3D design of a headset with an integrated microphone arm that acts as a switch to activate the PTT function, as well as a radio unit and a cable to connect the radio to the headset

workplace's architectural structure and design, the area's weather conditions and the plant's safety regulations. This, in turn, affects the ease with which the devices can be operated. Our findings support Hückler's statement that, 'if a product cannot be used because it is incomprehensible or because it interferes with or even prevents its application, then it cannot work technically-it will not even be put into operation; the primacy of use is essential' (Hückler 2000: 153; our translation). With this in mind, it is worthwhile to examine alternative solutions for today's PDAs and handheld radios. For example, smartphones equipped with radio-frequency identification could be mounted on the inside of the wrist and used instead of bulky PDAs, or headsets with integrated functions for selecting radio channels and setting the volume could replace traditional handheld radios. In Fig. 5, we show a simple concept based on Motorola's MTP850 Ex TETRA terminal; third-year undergraduate students at Østfold University College developed this concept. Considering the challenges described above, the students focused on the actual product determination: voice communication. The concept is characterized by its wearability (wearable accessory), tangibility (physical controls) and simple operating structure. 


\section{Discussion}

As we explored in our ethnographic fieldwork, in which we interviewed and observed operators on-site, we found that the implementation of handheld devices at oil and gas processing facilities had both advantages and disadvantages. The disadvantages stem from a gap between the technology and the user experience; this gap needs to be bridged. In our discussion, we focus on three themes. First, we consider the need for improved work practices in oil and gas workplaces, and then we describe the effects of mobile devices that are designed to facilitate efficient and safe plant operations and work routines in hazardous environments. Finally, we focus on understanding interaction design in the context of operators' activities.

\subsection{The need for improved work practices in oil and gas workplaces}

Other researchers have identified problems in work procedures related to the control of plant status and operational efficiency. For example, Farris and Medema (2012) explored portable handheld devices' ability to improve human performance and reduce human error in routine fieldwork. Oxstrand et al. (2013a) aimed to replace paperbased procedures with portable computer-based technologies. Jokstad (2010) and Kaarstad et al. (2012) tested handheld devices such as iPads and PDA to achieve more efficient communication, reduced workloads for plant operators and control-room operators, and better process overviews.

In line with these studies, we identified operations that proved to be difficult to handle with current, or even experimental, devices; we also identified improvements that could help mitigate these problems.

When properly designed and implemented, mobile technology can help plant operators in several areas. For example, work permit procedures could be quicker and more efficient through the use of mobile devices or digital writing solutions that do not require notepads, pens and radio communications. Optimally, mobile technologies would wirelessly communicate with the company's enterprise resource planning system. Such technologies could also help prevent incorrect information, delays, long-distance walks within the plant and unnecessary radio communication. However, each type of technology used (e.g. tablet computers, PDAs or smartphones) has both benefits and challenges.

\subsection{The effects that industrial mobile devices have on work routines in hazardous environments}

In terms of interaction design, our study made clear that users' acceptance of mobile devices is not only a question of menu structures and digital information presentation. Less sophisticated details, such as physical buttons, can affect the efficiency and safety of a task's execution. For example, five operators mentioned the accidentally use of the emergency button on the top of the MTP850 Ex TETRA terminal. Pressing this button activated an alarm in the central control room and locked the whole system. The risk of human error exists whenever people operate any technical equipment or instruments - that is, in every human-machine interaction-and engineers and designers must take this risk into account during the design process.

The emergence of mobile devices such as portable barcode scanners and radio-frequency identification scanners is making it possible for plant operators to more efficiently collect measurements such as oil levels, temperatures and pressures. Our evaluation of the handheld MC 9090ex-K PDA, however, showed potential for improvement in several areas. Although the use of a mobile data logger instead of printed checklists temporarily improved the routines at Nyhamna, we found that the device's design reduced the efficiency and safety of the work performance. For example, operators said that they sometimes forgot the device somewhere in the plant. For example, they would put the device away because they had to do other tasks, such as conducting maintenance or signing work permits. The PDA was too big to fit in a pocket or be clipped to a belt, so it could not be easily stored on a worker's body. This led to unnecessary travel back and forth within the plant or from the field to the office, which was time-consuming and stressful for operators. We also observed that rainfall had a negative impact on the use of the PDA because the barcode labels and the device's scan exit window both have to be clean and dry to scan successfully. When operators first must wipe the barcode labels and scan window dry, the process is even more time-consuming.

\subsection{Understanding interaction design in the context of operators' activities}

Modern mobile devices have more functions that older devices had. However, some devices offer several methods for performing the same function, such as obtaining feedback to indicate that the right function has been performed. For example, operators who use the MTP850 Ex TETRA terminal can send text messages by choosing one of three options-selecting "send" from the menu, pressing the send key or hitting the PTT button. However, several informants said that they did not use the messaging function at all. 
We argue that it is better to support and enhance task performance rather than design performance. Our empirical results have shown that the feature complexity in today's mobile technology challenges users. Devices such as the MTP850 Ex TETRA terminal are bloated with unnecessary features. For example, one informant noted that many of the TETRA terminal's available functions are not necessary, as he largely uses only PTT [operator: "We use it in a very simple way; we do not need a very advanced radio."]. User tasks are essential to the application of technology in practice. In our studies, the user tasks included constant radio communication between operators in the plant and those in the control room. In terms of physical activity, the plant operators had to cover long distances (often while walking), climb ladders and scaffolds (see Fig. 3a), and carry equipment (see Fig. 2a). These tasks have major impacts on interactions with handheld devices. From an interaction-design perspective, it is not enough to primarily consider mobile devices' graphical user interfaces and software technologies. Future solutions require the design of product interfaces and the inclusion of multiple sensory channels to increase the bandwidth of the user-mobile device interaction.

\subsection{Further research work}

Research has been conducted on, for example, the impact that various mobility situations have on stylus-based tapping performance in PDAs (Lin et al. 2007); on the effects that changes in motion, lighting and task type have on mobile-device users' performance and workload (Barnard et al. 2007); and on the relationship between walking speed and text-input performance (Mizobuchi et al. 2005). In particular, scholars have shown that walking affects interaction with mobile devices and have proposed systems for improving text entry on touchscreens while users are walking (e.g. Goel et al. 2012). However, many of these studies were carried out in simulated environments that had low stress factors and short distances. Given the many dependencies and environmental factors unique to oil and gas workplaces, more empirical research is needed on time-constrained, fast-paced and data-driven environments where humans must rapidly perceive data.

In the future, more research should be conducted to investigate how operators use mobile devices in various mobility situations and to generate quantifiable data on measure such as target selection, task-completion time, degree of attention and workload. Additional empirical studies are needed to understand the impact that motion and environmental conditions have on these parameters.

\section{Conclusion}

Operations in oil and gas plants are particularly challenging due to the environment, which is hazardous because of ignition or explosion danger and because of harsh weather conditions. We have shown that the current digital equipment is often inadequate, identified possible improvements and shown why those improvements are needed. In this study, we applied ethnographic methods and physical work analysis to gain an understanding of everyday work experiences and practices from the perspective of operators at Norwegian natural-gas processing plants. Our methods were relevant for the purposes of this research study, as they helped to uncover discrepancies between the ways in which mobile devices are designed and the reality of how operators interact with them. Moreover, the study's ethnographic approach ensured that we used hands-on experience to inform our insights.

However, conducting research in oil and gas workplaces can be challenging, as it is difficult to get permission to visit platforms and as safety regulations can limit on-site research activities. Some companies involved in the development of mobile applications have difficulty acquiring hands-on insight offshore, but such insight is important in achieving good design solutions.

Due to safety regulations and time constraints, our research focused on two mobile devices. Our aim in future work is to perform a meta-analysis of five handheld communication devices that are intended for use in various environments.

Acknowledgements We would like to acknowledge the Institute for Energy Technology for supporting this research. We also thank the participants of this study for their valuable time and detailed insights.

Open Access This article is distributed under the terms of the Creative Commons Attribution 4.0 International License (http://creativeco mmons.org/licenses/by/4.0/), which permits unrestricted use, distribution, and reproduction in any medium, provided you give appropriate credit to the original author(s) and the source, provide a link to the Creative Commons license, and indicate if changes were made.

\section{References}

Barclay A (2012) Tools: Transana. http://researchdata.wisc.edu/tools/ tools-transana/. Accessed 3 Apr 2017

Barnard L, Yi JS, Jacko JA, Sears A (2007) Capturing the effects of context on human performance in mobile computing systems. Pers Ubiquit Comput 11:81-96

Blandford A et al (2015) Strategies for conducting situated studies of technology use in hospitals. Cogn Technol Work 17:489-502

Blauhut D (2016) Handheld devices for use within integrated operations in the petroleum industry. Thesis for the Degree of Philosphiae Doctor, NTNU, Trondheim

Blauhut D, Buur J (2009) What video styles can do for user research. Engaging Artifacts, NORDES, Oslo 
Farrington-Darby T, Wilson JR (2009) Understanding social interactions in complex work: a video ethnography. Cogn Technol Work $11: 1-15$

Farris R, Medema H (2012) Advanced instrumentation, information and control (II\&C) research and development facility buildout and project execution of LWRS II\&C pilot project 3. Idaho National Laboratory, INL/MIS-12-25139

Goel M, Findlater L, Wobbrock J (2012) WalkType: using accelerometer data to accomodate situational impairments in mobile touch screen text entry. In: CHI ' 12 Proceedings of the SIGCHI conference on human factors in computing systems, pp 2687-2696

Harrison C, Hudson SE (2009) Providing dynamically changeable physical buttons on a visual display. In: CHI ' 09 proceedings of the SIGCHI conference on human factors in computing systems, pp 299-308

Heyer C (2009) High-octane work: the oil and gas workplace. In: ECSCW 2009, proceedings of the 11th European conference on computer supported cooperative work, Vienna, Austria, pp $363-382$

Heyer C (2010) Investigations of Ubicomp in the oil and gas industry. UbiComp 2010, Copenhagen, Denmark

Heyer C, Husøy K (2012) Interaction with the dirty, dangerous, and dull. ACM Interact 19(4):19-23

Hückler A (2000) Formbildungszwänge im Produktdesign. In: Scheuer W (ed) Lesebuch für Designer. Hohenheim Verlag, Stuttgart, Leipzig, pp 148-165
Jokstad H (2010) Experience of handheld computing from the HBWR 2008 experiment. Halden work report (HWR-942)

Kaarstad M, Strand S, Nihlwing C (2012) Use of a handheld device as a tool for process information updates in nuclear power plants. American nuclear society international topical meeting on nuclear plant instrumentation, control, and human-machine interface technologies, 8. NPIC\&HMIT 2012, San Diego, CA

Kuhlmann U (2012) Wischen und Fühlen. Neue Techniken für Touchscreens. In: c't 2012, vol 17, pp 146-149

Lin $M$ et al (2007) How do people tap when walking? An empirical investigation of nomadic data entry. Int J Hum Comput Stud 65:759-769

Mizobuchi S, Chignell M, Newton D (2005) Mobile text entry: relationship between walking speed and text input task difficulty. MobileHCI'05, September 19-22, Salzburg, Austria

Oxstrand J, Le Blanc K, Bly A (2013a) Computer-based procedures for field workers: results from three evaluation studies. Idaho National Laboratory, INL/EXT-13-30183

Oxstrand J, Le Blanc K, Fikstad C (2013b) Evaluation of revised computer-based procedure system prototype. Idaho National Laboratory, INL/EXT-13-28226

Senseg (2014) Web presence. http://senseg.com/. Accessed 4 July 2014 Sperschneider W, Bagger K, Buur J (2006) Ethnographic user studies. In: Buur J, Binder T (eds) User centred product design. University of Sothern Denmark, MCI, pp 49-52 